\title{
Determining the economic feasibility of hydraulic fracturing in a low-permeability formation area
}

\author{
Shakurova Alsu Fagimovna \\ Ufa State Petroleum Technological University, \\ Branch of the University in the City of Oktyabrsky, Russian \\ Federation \\ alsu0017@mail.ru
}

\author{
Shakurova Aigul Fagimovna \\ Ufa State Petroleum Technological University, \\ Branch of the University in the City of Oktyabrsky, Russian \\ Federation \\ afagim@mail.ru
}

\begin{abstract}
The article analyzes the economic performance of wells with hydraulic fracturing. The effectiveness of using hydraulic fracturing technology in the development of the oil reserve area with the low-permeability zone is defined in terms of its economic feasibility. To do this we studied the dependence of the net profit value of the enterprise, accumulated during the billing period, from the fracture length and the oil prices on the international market. As the estimates for calculating, we used the economic activity data of one of the oil-producing enterprises of Tatarstan. The dynamics of growth of the accumulated net profit value was studied taking into account the options and different fracture lengths in the low-permeability zone. It was found that the greater the fracture length is near injection wells in the low-permeability zone, the lower the accumulated net profit value is, and vice versa.
\end{abstract}

Keywords - formation model; skin factor; permeability; anisotropy; filtration; economic performance.

\section{INTRODUCTION}

The effectiveness of using hydraulic fracturing technology in the development of the oil reserve area with the lowpermeability zone is defined in terms of its economic feasibility. To do this we studied the dependence of the net profit value of the enterprise, accumulated during the billing period, from the fracture length and the oil prices on the international market.

As the estimates for calculating, we used the economic activity data of one of the oil-producing enterprises of Tatarstan.

The scope of the economic feasibility of using the technology is determined by the choice of such values as the fracture length $\mathrm{L}$, when the total growth (relative to the basic version) of the accumulated net profit value for all the time of oil production (reaching the maximum water content) is $\Delta \Sigma \operatorname{NPV}\left(\mathrm{Q}_{0}, \mathrm{q}\right)>0$.

\section{MATERIALS AND METHODS}

Net profit value (NPV) is calculated in accordance with the Rules of preparing the process design package for development of oil and gas-and-oil fields (RD 153-39-00796), "Methodological recommendations for assessing the efficiency of investment projects", publishing house "Ekonomika", Moscow, 2000; "Methodical recommendations on designing the development of oil and gas-and-oil fields", Moscow, 2007.

\section{THE CONTENTS OF THE METHOD AND EVALUATION OF ITS EFFECTIVENESS}

Economic performance was calculated for the two cases of localizing the low-permeability zones of the formation according to four variants of the model area development [1, 2]. There was considered the basic version (without hydraulic fracturing), the first, the second and the third versions.

The optimal fracture length was determined at hydraulic fracturing.

According to the calculations [3, 4], the maximum operational benefit (incremental oil production) is achieved in terms of maximum fracture length (in the considered intervals). However, on the other hand, a condition imposing a limit on the fracture length includes the economic criteria defined by the cost of materials and related works when carrying out hydraulic fracturing [5-7].

The following is the procedure for determining the optimal (in terms of economic performance) values of the fracture length of the hydraulic fracturing. It is obvious that the hydraulic fracturing design is defined by the required operational benefit of the hydraulic fracturing and the economic performance characterizing the event profitability.

The required volume of proppant is defined by the fracture length and its height and width, i.e. depends on $\mathrm{L}$, if having constant values of the collector thickness and the openness of fractures: $V_{\text {proppant }}=f(L)$.

The volume of incremental oil production is also a function of L. Therefore, it is possible to determine the dependence of the volumes of incremental oil production on the cost of formation hydraulic fracturing. In addition, the use of hydraulic fracturing leads to a change in the volume of produced water and the volume of the injected displacement agent. In determining the optimal technology parameters (in terms of economic performance) we must consider the growth of sales volumes, cost changes of associated water production and displacement agent injection, increase of costs associated with the implementation of the hydraulic fracturing technology [8-11]. 
Thus, the economic performance, which is the growth of the accumulated net profit value of the enterprise $\left(\sum \Delta N P V\right)$ relative to the basic version over the considered time period, is a function of the technology options (fracture length). The maximum of this value corresponds to the optimal options of the implemented hydraulic fracturing technology.

The change in the implementation volumes through the application of the hydraulic fracturing technology constitutes the following value per unit of time (year, month):

$$
\Delta H=P_{\text {oil }} \Delta q_{\text {oil }}+P_{\text {gas }} \Delta q_{\text {gas }},
$$

where $\mathrm{P}_{\text {oil }}$ is the oil price (without VAT), rubles per ton of oil,

$\mathrm{P}_{\mathrm{gas}}$ - the price of associated gas, rubles per $1000 \mathrm{cbm}$ of gas,

$\Delta \mathrm{q}_{\mathrm{oil}}, \Delta \mathrm{q}_{\mathrm{gas}}$ - the change in oil production (tons) and gas $\left(10^{3} \mathrm{cbm}^{\prime}\right.$ per unit of time through the use of the technology.

The change in operating costs associated with the use of technology is:

$$
\begin{aligned}
& \Delta E_{\text {oc }}=\Delta E_{\text {collection }}+\Delta E_{\text {processing }}+\Delta E_{\text {lifting }}+ \\
& \Delta E_{\text {injection }}+\Delta E_{\mathrm{EOR}},
\end{aligned}
$$

where $\Delta \mathrm{E}_{\text {collection }}, \Delta \mathrm{E}_{\text {processing }}, \Delta \mathrm{E}_{\text {lifting }}, \Delta \mathrm{E}_{\text {injection, }}, \Delta \mathrm{E}_{\mathrm{EOR}}$ are the changes in operating costs for collection and transportation of liquid and gas, oil processing, the energy cost of liquid lifting, formation pressure maintenance, implementation of hydraulic fracturing technology.

$$
\Delta E_{\text {collection }}=\Delta q_{\text {liq }} T_{\text {liq }}+\Delta q_{\text {gas }} T_{\text {gas }}
$$

where $\Delta \mathrm{q}_{\text {liq }}$ is a change in liquid lifting associated with the use of the technology $(\mathrm{t})$,

$\mathrm{T}_{\text {liq }}$ - standard for the collection and transportation of liquid, rubles per ton, of liquid,

$\mathrm{T}_{\text {gas }}$ - standard for the collection and transportation of gas, rubles per $1000 \mathrm{cbm}$ of gas.

$$
\Delta E_{\text {processing }}=\Delta q_{\text {liq }} D_{\text {liq }},
$$

where $\mathrm{D}_{\text {liq }}$ is the standard for the oil processing, rubles per ton of liquid,

$$
\Delta E_{\text {lifting }}=\Delta q_{\text {liq }} U_{\text {liq }},
$$

where $\mathrm{U}_{\text {liq }}$ is the standard for the energy cost on the liquid lifting, rubles per ton of liquid.

$$
\Delta E_{\text {injection }}=\Delta q_{\text {injection }} W_{\text {injection }}
$$

where $\Delta \mathrm{q}_{\text {injection }}$ - a change in the water injection associated with the use of the technology (cbm),

$\mathrm{W}_{\text {injection }}-$ the standard for formation pressure maintenance, rubles per cbm of injection.

$$
\Delta E_{\mathrm{EOR}}=C_{1}+C_{2}(R),
$$

where $C_{1}$ is a semi-constant component of the costs of the technology implementation (the cost of the works, etc.),

$\mathrm{C}_{2}(\mathrm{R})$ is a conditionally variable component of the costs depending on the size of the created fracture (the cost of the agent, etc.).

The technology associated change in taxes and payments included in the production cost is described as the following:

$$
\Delta Y=\Delta q_{\text {oil }} N_{\text {oil }},
$$

where $\mathrm{N}_{\text {oil }}$ is the tax on mining (oil), rubles per ton.

The change in all operating costs associated with the use of the technology is described as the following:

$$
\Delta E=\Delta E_{\mathrm{oc}}+\Delta Y,
$$

The change in the balance sheet profit of the enterprise associated with the use of the technology can be represented as:

$$
\Delta G=\Delta H-\left(\Delta E+\Delta S_{\mathrm{VAT}}\right), \quad(10)
$$

where $\Delta \mathrm{S}_{\mathrm{VAT}}$ is a change in VAT associated with the use of the technology.

$$
\Delta S_{\mathrm{VAT}}=P_{o i l} \Delta q_{\mathrm{oil}} Y_{\mathrm{VAT}},
$$

where $\mathrm{Y}_{\mathrm{VAT}}$ is the standard of the VAT, MU

The change in the enterprise profit tax associated with the use of the technology is represented as:

$$
\Delta A=\Delta G Y_{\text {profit }},
$$

where $\mathrm{U}_{\text {profit }}$ is the standard of income tax, $\mathrm{MU}$

The net profit value of the company acquired from the implementation of the technology will be:

$$
\Delta F=\Delta G-\Delta A,
$$

Then the change in NPV is:

$$
\Delta N P V_{t}=\Delta F /\left(1+d^{t-1}\right),
$$

where $\mathrm{t}$ is the time step,

$\mathrm{d}-$ the discount factor.

The analyzed increase in net profit value of the enterprise, as the function of the technology options, gained from using the technology will be presented in the form of:

$$
\sum \Delta N P V=\sum_{t=1}^{T} \Delta N P V_{t}
$$

Figure 1 shows the dynamics of the calculated growth (relative to the basic version) of net profit value according to the versions for two positions of the reduced-permeability zone relative to the number of injection wells. At the same time, the increase of water extraction for the case of hydraulic fracturing in the low-permeability zone, located near the injection row, leads to a decrease in economic efficiency of development (figure 1A). It should be noted that the maximum growth ANPV is characteristic of the case being considered. This is explained, in this case, with the rise of the operational benefit in the first years after hydraulic fracturing operations at the well WPRD4 when the net profit discounting is pretty small. For the case of the remote location of the lowpermeability zones, the growth of hydraulic fracturing effect at the well WPRD2 occurs more slowly, thus the net profit discounting is much higher.

By the end of reserves production, the greatest economic efficiency is characteristic of the version with the maximum fracture length of the formation hydraulic fracturing in the low-permeability zone, being remote from the row of injection wells. In this case, the final value of the ANPV increase through the use of the hydraulic fracturing technology is several times lower than its maximum value. The sharp decline in economic efficiency of development is connected with the watering of the development wells.

Shown in figure 1, the dynamics of economic performance - ANPV - indicate the low efficiency of hydraulic fracturing in the low-permeability area, located in the vicinity of injection wells. The use of hydraulic fracturing in the lowpermeability zone, remote from the row of injection wells, is characterized by a positive economic effect. 

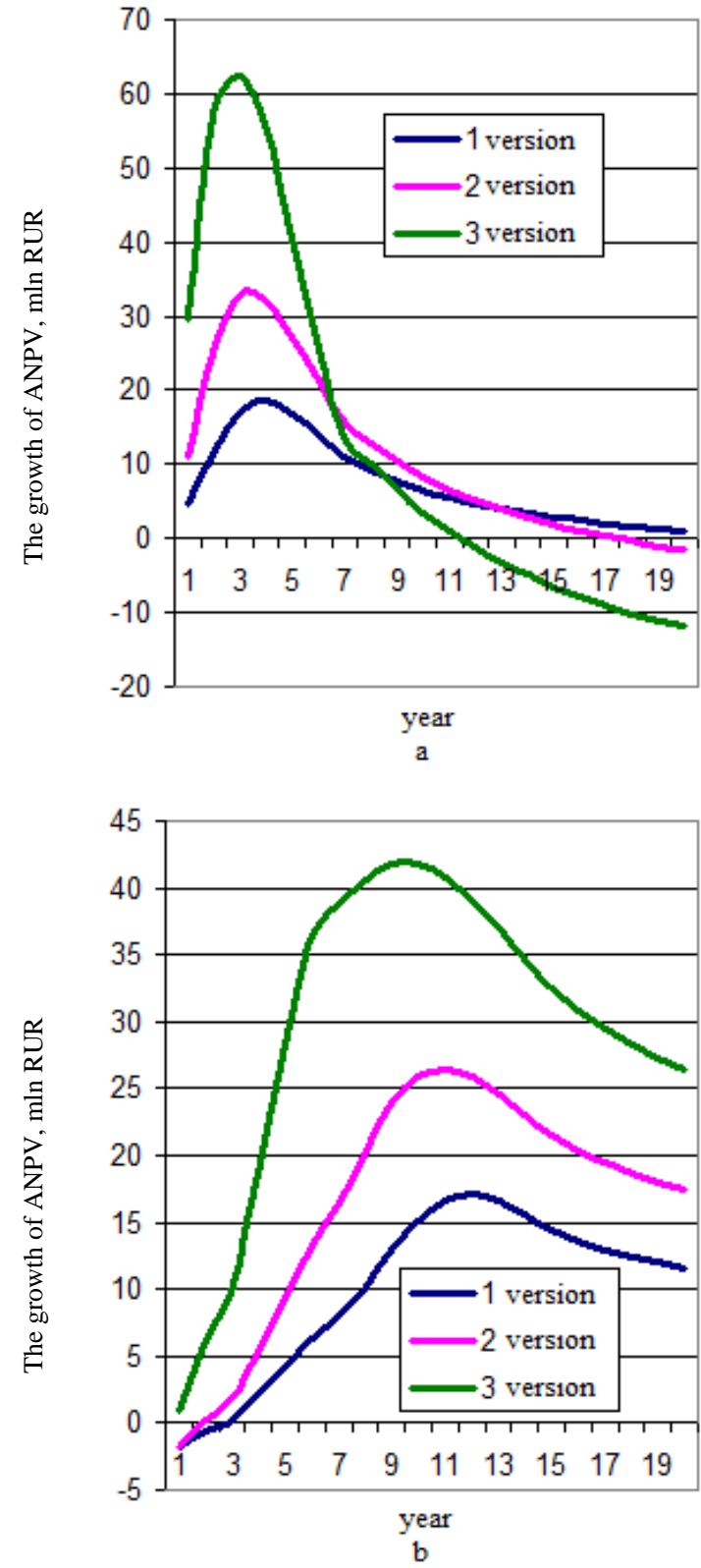

Fig. 1. The growth dynamics of ANPV through the use of the hydraulic fracturing technology according to the versions concerning the development of an area with a different arrangement of reduced-permeability zones relative to the row of injection wells: $\mathrm{a}$ - nearby, $\mathrm{b}$ - at a distance.

The dependence of the economic effect on the fracture length is shown in figure 2 and in table 1 . In the case when hydraulic fracturing is conducted in a low-permeability zone, localized near the injection wells (figure $2 \mathrm{~A}$ ), the curve of the economic effect reaches the maximum at $\mathrm{L}=50 \mathrm{~m}$. Thus, the hydraulic fracturing reveals the area of a low-permeability reservoir, representing a small fraction of the total volume of the low-permeability zones. Despite the IRR increase due to the use of hydraulic fracturing with fractures of different length, the volume increase of produced water significantly reduces the technology effectiveness at large fractures.
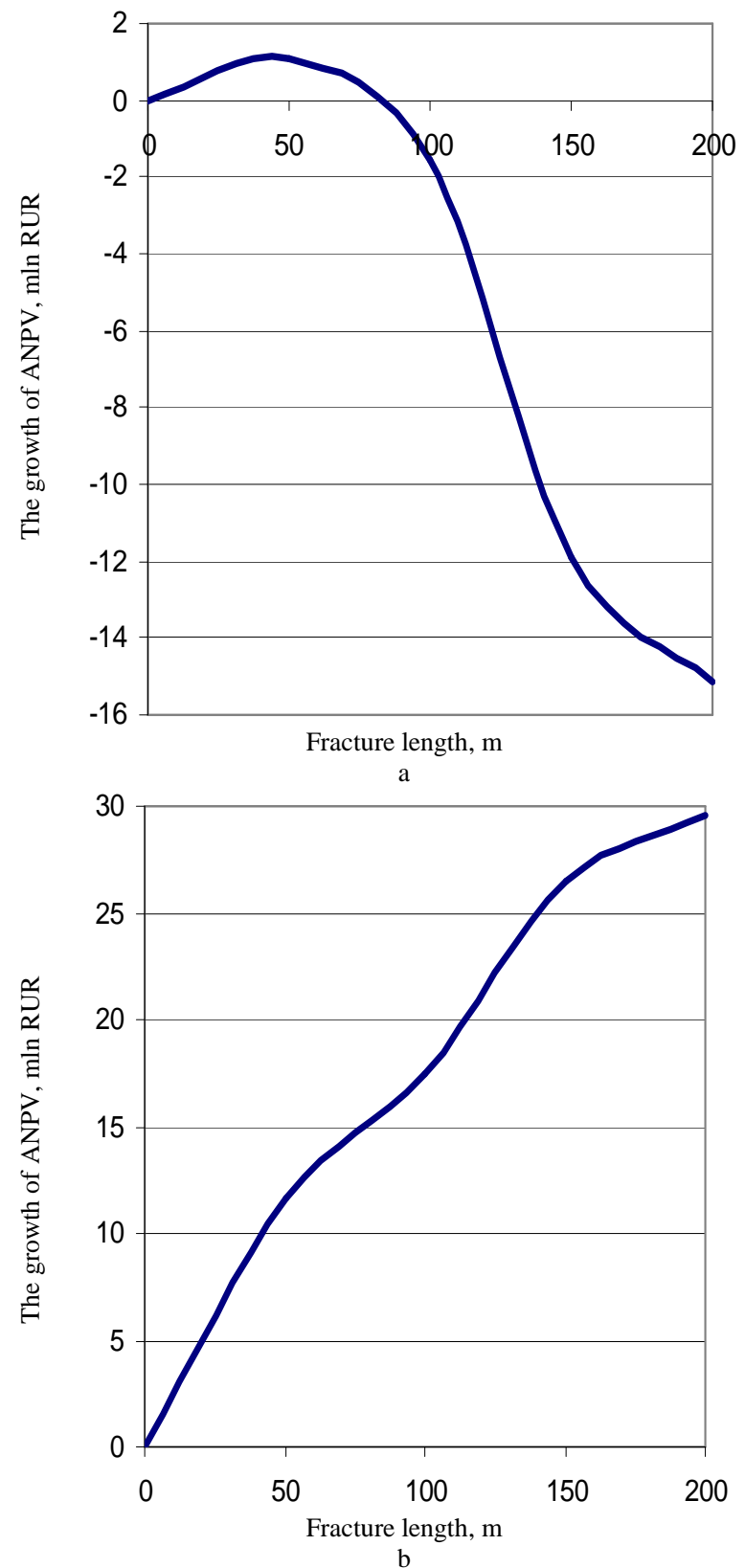

Fig. 2. The dependence of the ANPV growth on the fracture length for different positions of the low-permeability zones relative to the injection wells through the use of hydraulic fracturing: $a-$ nearby, $b$ - at a distance.

Unlike the considered case (a), hydraulic fracturing in the low-permeability zone of a collector, remote from the injection wells, all considered versions with different fracture lengths have positive economic effects. 
TABLE I. THE MAIN TECHNICAL AND ECONOMIC INDICES OF HYDRAULIC FRACTURING VERSIONS DEPENDING ON THE FRACTURE LENGTH. A - A LOW-PERMEABILITY ZONE IS NEAR THE INJECTION WELLS, B - A LOWPERMEABILITY ZONE IS LOCATED AWAY FROM THE INJECTION WELLS

A (A WELL WPRD4)

\begin{tabular}{|c|c|c|c|}
\hline $\begin{array}{c}\text { fracture length, } \\
\mathbf{m}\end{array}$ & $\begin{array}{c}\text { hydraulic } \\
\text { fracturing cost, } \\
\text { mln RUR }\end{array}$ & $\begin{array}{c}\text { IRR growth, } \\
\mathbf{1 0 0 0} \mathbf{~ c b m}\end{array}$ & $\begin{array}{c}\text { ANPV growth, } \\
\text { mln RUR }\end{array}$ \\
\hline 50 & 4.5 & 4.31 & 1.07 \\
\hline 100 & 6.5 & 9.02 & -1.57 \\
\hline 150 & 8.5 & 12.65 & -11.91 \\
\hline 200 & 10.5 & 14.10 & -15.13 \\
\hline
\end{tabular}

B (A WELL WPRD2)

\begin{tabular}{|c|c|c|c|}
\hline $\begin{array}{c}\text { fracture length, } \\
\mathbf{m}\end{array}$ & $\begin{array}{c}\text { hydraulic } \\
\text { fracturing cost, } \\
\text { mln RUR }\end{array}$ & $\begin{array}{c}\text { IRR growth, } \\
\mathbf{1 0 0 0} \mathbf{~ c b m}\end{array}$ & $\begin{array}{c}\text { ANPV growth, } \\
\text { mln RUR }\end{array}$ \\
\hline 50 & 4.5 & 15.98 & 11.63 \\
\hline 100 & 6.5 & 21.26 & 17.52 \\
\hline 150 & 8.5 & 27.13 & 26.45 \\
\hline 200 & 10.5 & 30.20 & 29.57 \\
\hline
\end{tabular}

\section{CONCLUSION}

If the low-permeability zone is located away from the injection wells, the use of hydraulic fracturing at the well, localized in this area, is technologically and economically efficient, and the longer the fracture is, the greater the effect is.

If the low-permeable zone is near the injection wells, the use of hydraulic fracturing at the well, localized in this area, is technologically efficient, and the longer the fracture is, the higher the technological effect is (incremental oil production). However, economic calculations show that, due to the considerable growth of the produced water volume, the economic effect of hydraulic fracturing becomes negative when the fracture lengths are over 70-80 meters.
The economic performance was calculated for the two cases of localization of the low-permeability zones. It is established that if there is a choice of unwatered lowpermeability zones for hydraulic fracturing, it is necessary to select the areas remote from the injection wells. Such a choice would maximize the technical and economic efficiency.

\section{References}

[1] I.V. Vladimirov, T.F. Manapov, A.F. Shakurova, Substantiation of the choice of a mathematical model for the estimation and distribution of the effect from fracturing in a single well to the surrounding oil, Oilfield Engineering, M.: OAO «VNIIOENG», No. 1, pp. 57-58, 2012.

[2] I.V. Vladimirov, T.F. Manapov, A.F. Shakurova, On some features of modelling of hydraulic fracturing of a layer, Oilfield Engineering, M.: OAO «VNIIOENG», No. 1, pp. 59-60, 2012.

[3] I.V. Vladimirov, A.F. Shakurova, A.V. Argilovski, V.V. Vasiliev, Effect of the orientation and extent of the fracture on the oil recovery factor and the density of the well grid, Oilfield Engineering, M.: OAO «VNIIOENG», No. 1, pp. 79-81, 2012.

[4] A.F. Shakurova, Analysis of a set of factors affecting the efficiency of hydraulic fracturing at the fields of OAO TATNEFT, Oilfield Engineering, M .: OAO VNIIOENG, Vol. 8, pp.23-27, 2014.

[5] M.J. Economides, K.G. Nolte, Reservoir Stimulation, Prentice Hall, Eglewood Cliffs, New Jersey, 07632, 1989.

[6] J.L. Gidley, S.A. Holditch, D.E. Nierode, R.W. Veatch, Recent advances in hydraulic fracturing, Monograph Series. SPE of AIME, Richardson, TX, 1989.

[7] C.A. Meese, M.E. Mullen, R.D. Barree, Offshore hydraulic fracturing technique, J. Petrol. Technol, V. 46, No. 3, pp. 226-229, 1994.

[8] M.E. Mullen, W.D. Norman, J.D. Wine, B.R. Stewart, Investigation of height growth in frac-pack completions, Paper SPE 36458, 1996.

[9] C.M. Pearson, A.J. Bond, M.E. Eck, J.H. Schmidt, Results of stressoriented and aligned perforating in fracturing deviated wells, J. Petrol. Technol, V. 44, No. 1, pp. 10-18, 1992.

[10] N.R. Warpinski, Z.A. Moschovidis, C.D. Parker, I.S. Abou-Sayed, Comparison study of hydraulic fracturing models - Test case: GRL staged field experiment, No. 3, SPE Prod. \& Fac, No. 1, pp. 7-18, 1994.

[11] J. Weaver, et al., «Application of new viscoelastic fluid technology results in enchanced fracture productivity», Paper SPE 71662, presented at the 2001 SPE Annual Technical Conference and Exhibition, New Orleans, Louisiana, September 30-October 3. 